\title{
Bir üniversite hastanesi’nin intrauterin inseminasyon deneyimi: Gebelik oranı ve ilișkili faktörler
}

\section{Intrauterine insemination experience of a university hospital: Pregnancy rate and associated factors}

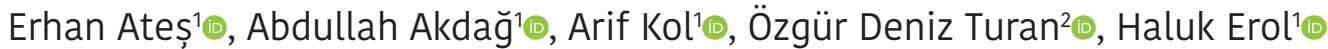

\section{öz}

AMAC̦: İntrauterin inseminasyon (IUI) diğer yardımcı üreme tekniklerine göre daha ucuz, kolay uygulanabilir ve daha az invazif olması nedeniyle ilk seçenek tedavi yöntemi olarak kabul edilmektedir. Bu çalışmada bir üniversite hastanesi infertilite ünitesinde IUI sonuçlarının değerlendirilmesi ve başarıyı etkileyen erkek faktörlerinin ortaya konulması amaçlandı.

GEREC ve YÖNTEMLER: Ekim 2017-Ocak 2020 tarihleri arasında infertilite ünitesine başvuran ve IUI yapılan çiftlerin verileri retrospektif olarak değerlendirildi. Hastaların yaş, başlangıç total sperm sayısı ve progresif motil sperm yüzdesi, yıkama sonrası total motil sperm sayısı (TMSC) ve yüzdesi gibi semen verileri kaydedildi. Dansite gradient yöntemiyle hazırlanan spermler ile tek inseminasyon sonrası $\mathrm{B}-\mathrm{hCG}$ testi pozitif olup transvajinal ultrasonografi (USG) ile gebeliği konfirme edilen hastalar gebe olarak kabul edildi ve IUI başarı kriteri olarak değerlendirildi. Semen parametreleri ile gebelik başarısı arasında ilişki uygun istatistiki yöntemlerle değerlendirildi.

BULGULAR: Klinik gebelik oranı IUI uygulanan 146 çiftte \%19,2, erkeğin verileri tam olan 136 çiftte ise $\% 19,9$ olup 136 erkeğin yaş ortalaması 30,34 $\pm 5,94$ yıl idi. Yaş ile IUI başarısı arasında istatistiksel olarak anlamlı ilişki saptanmamakla birlikte yaş arttıkça başarı şansının düştüğü görüldü $(\mathrm{p}=0,316)$. Semen volümü $(\mathrm{p}=0,228)$, yıkama öncesi TMSC $(\mathrm{p}=0,187)$, yıkama öncesi progresif motil sperm sayısı $(\mathrm{p}=0,128)$ ile gebelik oranları arasında istatistiksel olarak anlamlı bir ilişki saptanmadı. Yıkama sonrası progresif motil sperm yüzdesi arttıkça gebelik şansı istatistiksel olarak anlamlı bir şekilde arttığı görüldü ( $\mathrm{p}=0,04)$, ancak yıkama sonrası TMSC ile bu ilişki saptanmadı $(\mathrm{p}=0,143)$. Başlangıç progresif motil sperm sayısı yüksekliği ile yıkama sonrası sperm sayısı arasında korelasyon saptandı (r: $0,286, \mathrm{p}<0,001)$.

SONUÇ: Açıklanamayan infertilite olgularında IUI gebelik oluşumunda etkili ve güvenli bir yöntem olup inseminasyon öncesi ve yıkama sonrası semen parametreleri başarıyı etkileyen faktörlerdendir.

Anahtar Kelimeler: İnfertilite, intrauterin inseminasyon, semen analizi, dansite gradient santrifüj
${ }^{7}$ Aydın Adnan Menderes Üniversitesi Tıp Fakültesi, Üroloji Anabilim Dalı, Aydın, Türkiye ${ }^{2}$ Aydın Adnan Menderes Üniversitesi Tıp Fakültesi, Kadın Hastalıkları ve Doğum Anabilim Dalı, Aydın, Türkiye

\section{Yazısma Adresi/ Correspondence:}

Dr. Öğr. Üyesi Erhan Ateş

Aydın Adnan Menderes Üniversitesi Tıp Fakültesi, Üroloji Anabilim Dalı, 09010,

Aydın, Türkiye

Tel: $\quad$ +905065323143

E-mail: drerhanates@yahoo.com

Gelis/ Received: $\quad 20.10 .2020$

Kabul/ Accepted: $\quad 01.12 .2020$

\section{ABSTRACT}

OBJECTIVE: Intrauterine insemination (IUI) is considered as the first choice treatment method because it is cheaper, easily applicable and less invasive compared to other assisted reproductive techniques. The specific objective of this study was to evaluate the IUI results and to reveal the male factors affecting success in a university hospital infertility unit.

MATRERIAL and METHODS: The data of the couples who applied to the infertility unit between October 2017 and January 2020 and underwent IUI were retrospectively evaluated. Semen analysis results such as initial total sperm count, progressive motile sperm percentage, post-washing TMSC and percentage, and ages of patients were recorded. To identify IUI success the following parameters were used: Patients whose $3-h C G$ test was positive after single insemination with sperm prepared by density gradient centrifugation and whose pregnancy was confirmed by transvaginal USG. Relationship between semen parameters and pregnancy success rates was evaluated using appropriate statistical methods.

RESULTS: Clinical pregnancy rate was $19.2 \%$ in 146 couples who underwent IUI, 19.9\% in 136 couples whose data were complete. Mean age of 136 men was $30.34 \pm 5.94$ years. Although there was no significant relationship between age and IUI success, it was observed that the success rate decreased as age increased $(\mathrm{p}=0.316)$. No statistically significant correlation was found between semen volume $(\mathrm{p}=0.228)$, TMSC before washing $(\mathrm{p}=0.187)$, progressive motile sperm before washing $(\mathrm{p}=0.128)$ and pregnancy rates. It was observed that as the percentage of progressive motile sperm after washing increased, the pregnancy rate increased significantly $(\mathrm{p}=0.04)$, but this relationship was not found with the total motile sperm count after washing $(\mathrm{p}=0.143)$. There was a correlation between initial progressive motile sperm count and sperm count after washing (r: $0.286, \mathrm{p}<0.001)$.

CONCLUSION: In the treatment of unexplained infertility cases, IUI is an effective and safe method for pregnancy. Semen parameters before insemination and after washing are among the factors affecting success rates. Keywords: Infertility, intrauterine insemination, semen analysis, centrifugation, density gradient

\section{Gíriș}

Üreme çağındaki çiftlerin yaklaşık \%10-15’i korunmasız düzenli cinsel ilişkiye rağmen, 12 ay içinde gebelik elde edilememesi olarak tanımlanan infertilite sorunu yaşamaktadırlar. İnfertilite etiyolojisinde \%30-40 erkek faktör, \%40-50 kadın faktör, \%20-25'inde her iki faktör birden rol oynarken olguların \%10-15'inde infertilite nedeni bulunamamaktadır. ${ }^{[1,2]}$ Yardımcı üreme tekniklerinin 
(YÜT) gelişmesiyle beraber, infertilite tedavisinde başarı oranları artmaya başlamıştır. Bunlar arasında intrauterin inseminasyon (IUI) diğer yardımcı üreme tekniklerine göre daha ucuz, kolay uygulanabilir ve daha az invazif olması nedeniyle ilk seçenek tedavi yöntemi olarak kabul edilmektedir. ${ }^{[3,4]}$ İntrauterin inseminasyon yönteminde, çeşitli tekniklerle hazırlanmış sperm uterus içerisine enjekte edilerek gebelik elde edilmeye çalışılmaktadır. İntrauterin inseminasyonun ardındaki mantık, servikal-mukus bariyerini atlamak ve fertilizasyon bölgesinde normal formlarla hareketli spermatozoa sayısını arttırmaktır. İntrauterin inseminasyon sonrası gebelik oranları \%10-20 arasında değişmekte olup bu oranlar üzerine erkek faktörlerini de içeren çeşitli durumların etkisi bulunmaktadır. ${ }^{[5]}$

Erkeğin değerlendirmesi semen analizi ile başlar. Sonuçların yorumlanması toplama tekniği, analiz yöntemi ve normal değerler gibi birçok değişkene bağlıdır. Geleneksel olarak sperm sayısı, hareketliliği ve normal morfolojiye sahip sperm yüzdesi, semen kalitesini değerlendirmek için kullanılan kriterlerdir. Dünya Sağlık Örgütü’nün (WHO) semen analizi için referans değerleri yaygın olarak sperm kalitesini değerlendirmek için kullanılsa da, başarılı IUI için semen özelliklerine göre tahmini sperm parametreleri ve eşik değerleri hala tartışmalıdır. ${ }^{[6]}$ Çalışmalar, IUI uygulanan çiftlerde hangi standart semen parametresinin gebelik oranlarını daha fazla etkilediğini ortaya koymaya çalışmakta ve buna göre sperm hareketliliği en öngörücü semen parametresi, Total Motil Sperm Sayısı [TMSC] da en öngörücü indeks olarak gösterilmektedir. ${ }^{[7-12]}$ Ombelet ve ark., 2014 yılında yaptıkları sistematik literatür incelemesinde IUI başarısı ile en iyi korelasyon gösteren sperm TMSC'nin 5-10 milyon aralığında olduğunu bildirmiştir. ${ }^{[13]}$ Sperm sayısının yanında kalitesi de başarıda önemli bir faktördür. İntrauterin inseminasyonda, in vitro sperm hazırlama teknikleriyle hareketsiz sperm, lökosit ve seminal plazmanın izolasyonunu takiben morfolojik olarak normal ve hareketli spermatozoanın temini esastır. ${ }^{[14]}$ İntrauterin inseminasyonda sperm hazırlanması için en çok kullanılan yöntemler: çeşitli kültür ortamları kullanarak spermin basit yıkanması, spermin self-migrasyonuna dayalı swimup yöntemi ve Density Gradient Centrifugation (DGC) yöntemidir. DGC yöntemi, in-vivo koşulları taklit eden in-vitro koşullar oluşturularak normal ve anormal spermlerin yoğunluk farklılıklarına göre ayrıldığı, böylece en iyi hareket ve morfoloji özelliklerine sahip spermlerin elde edildiği bir tekniktir. ${ }^{[15,16]}$

Bu çalışmada DGC yöntemi ile hazırlanan spermleri kullanarak gerçekleştirilen IUI sonuçlarımızı değerlendirmeyi ve başarıyı etkileyen erkek faktörlerini ortaya koymayı amaçladık.

\section{GEREÇ ve YÖNTEMLER}

Lokal etik komite onayının ardından (Protokol No: 2020/188) Ekim 2017-Ocak 2020 tarihleri arasında hastanemizin fertilite ünitesine başvuran ve IUI yapılan çiftlerin verileri retrospektif olarak değerlendirildi. Hastaların yaş, başlangıç total sperm sayısı ve progresif motil sperm yüzdesi, yıkama sonrası TMSC ve yüzdesi gibi semen verileri kaydedildi. Tüm sikluslarda rekombinant koriogonadotropin alfa uygulandiktan 36 saat sonra tek inseminasyon yapilan hastalardan hCG gününden sonraki 14 gün içinde mens olmayanlara $\beta$-hCG testi yapıldı. Test pozitifliği olan hastalara iki hafta sonra transvajinal USG uyguland. USG ile gebeliği konfirme edilen hastalar gebe olarak kabul edildi ve IUI başarı kriteri olarak değerlendirildi. Aylara göre başarı durumu kaydedildi. Tıbbi kayıtların tamamına ulaşlamayan hastalar bu çalışmanın dışında tutuldu.

\section{Sperm Hazırlığı}

İnseminasyondan iki saat önce 2-5 günlük cinsel perhiz sonrası laboratuvarda mastürbasyon yoluyla elde edilen semen örnekleri steril kapta toplandi. Likefaksiyon sonrası WHO kriterlerine göre semen analizi yapılarak başlangıç değerleri kaydedildi. Steril disposible santrifüj tüpüne steril bir şırınga ile $2 \mathrm{ml}$ üst faz konuldu. Üst fazın altına $2 \mathrm{ml}$ alt faz yavaşça enjekte edildi. Steril bir enjektör ile $2 \mathrm{ml}$ likefiye semen en üste ilave edildi. Santrifüj tüpü öncelikle iki tabakalı 1900 devir/dk 400 g (\%45- \%90 dansitede) 20 $\mathrm{dk}$ santrifüj edildikten sonra oluşan süpernatant pelletten uzaklaştırıldı. Sonra pellet $10 \mathrm{ml}$ (Sil-Select Plus ${ }^{\mathrm{T}}$, Fertipro N. V. Beernem, Belgium) sperm yıkama sıvısına alındı. Bu solüsyon $10 \mathrm{dk} 1900 \mathrm{devir} / \mathrm{dk} 400 \mathrm{~g}$ ile santrifüj edilip 0,7 $\mathrm{ml}$ sperm pelleti inseminasyon için uygun hale getirildi.

\section{İnseminasyon Tekniği}

Menstrüel siklusun 11. ve 13. günleri arasında transvajinal ultrasonografi takibi sırasında 16 mm'den büyük herhangi bir folikül için iki dikey düzlemdeki ölçümlerden ortalama folikül çapı hesaplandı. Ortalama çapı 18 mm'den büyük en az bir folikül varlığında IUI planlandı. İntrauterin inseminasyon, $250 \mu \mathrm{g}$ rekombinant koriogonadotropin alfa uygulanmasından 36 saat sonra her seferinde aynı uygulayıcı tarafından (ÖDT) gerçekleştirildi. Tüm hastalardan inseminasyon işlemi için idrara sıkışı olarak gelmeleri istendi. Serviks $2-3 \mathrm{ml}$ serum fizyolojik ile silindi ve inseminasyon kateteri (C. C. D. Laboratoire, Paris, France) serviks içinden ilerletilerek, fundusa değene kadar nazikçe uterus içine yerleştirildi. Daha sonra $-1 \mathrm{~cm}$ geri çekildi ve pistonun yavaş hareketiyle sperm enjekte edildi. Hastalar 
işlem sonrası 15 dakika yatış pozisyonunda dinlendirildi. Tüm hastalara IUI sonrası ikinci günden itibaren 12 gün boyunca progesteron ile luteal faz desteği yapıldı. Hastaların gebe olup olmadıkları işlem sonrası 14. gün serum beta HCG ile değerlendirildi.

\section{Istatistiksel Analiz}

İstatistiksel analiz için veriler SPSS software (ver.21,0 for Windows; SPSS Inc, Chicago, IL, USA) programına aktarıldı. Verilerin değerlendirilmesi için ki-kare testi uygulandi. $\mathrm{p}<0,05$ istatistiksel olarak anlamlı kabul edildi.

\section{BULGULAR}

İntrauterin inseminasyon uygulanan toplam 146 infertil çiftin değerlendirildiği çalışmamızda verileri tam olan 136

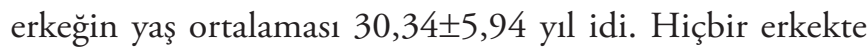
sistemik bir hastalık yoktu. 18 erkekte geçirilmiş varikoselektomi öyküsü vardı. Altı erkekte fizik muayenede sol varikosel saptanmış olmasına rağmen değerlendirmeler sonucunda bunların hiçbirisinde fertilizasyonu olumsuz şekilde etkileyecek bir semen analizi veya testis anormalliği tespit edilmedi. Klinik gebelik oranı IUI uygulanan 146 çiftte \%19,2, erkeğin verileri tam olan 136 çiftte ise \%19,9 olup aylara göre dağılım Şekil 1'deki gibidir.

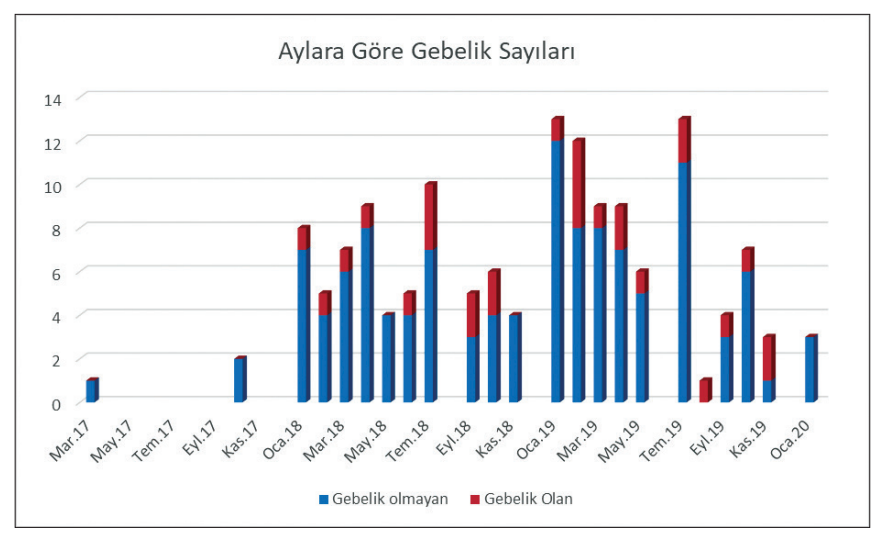

Şekil 1. Aylara göre IUI/Gebelik dağııııı.

İnseminasyon işleminde kullanılan sperm pelletlerinde total sperm sayısının 2,1 milyon ile 108,5 milyon arasında değiştiği görüldü. İnseminasyon sonrası başarılı gebelik oluşan hastalardaki pelletlerde total sperm sayısı ortanca değeri 34,8 (7,7-96,6) milyon olarak saptandı.

Semen volümü ile gebelik oranları karşılaştırıldığında istatistiksel olarak anlamlı bir ilişki saptanmadı $(\mathrm{p}=0,228)$. Yıkama öncesi TMSC ile gebelik oranları arasında istatistiksel olarak anlamlı bir ilişki saptanmadı $(\mathrm{p}=0,187)$. Yıkama öncesi progresif motil sperm sayısı ile gebelik oranları karşılaştırıldı. Progresif motil sperm sayısı arttıkça başarının özellikle > $20 \mathrm{mil} / \mathrm{cc}$ sperm sayısında arttığı görüldü ancak istatistiksel olarak anlamlı saptanmadı $(\mathrm{p}=0,128)$. Yıkama sonrası progresif motil sperm yüzdesi arttıkça gebelik şansı istatistiksel olarak anlamlı bir şekilde arttığı görüldü $(\mathrm{p}=0,04)$. Başlangıç progresif motil sperm sayısı yüksekliği ile yıkama sonrası sperm sayısı arasında korelasyon saptand 1 (r: 0,286, p<0,001). Ancak yıkama sonrası TMSC ile gebelik başarısı arasında anlamlı ilişki saptanma$\mathrm{d}_{1}(\mathrm{p}=0,143)$. Yaş ile IUI başarısı arasında istatistiksel olarak anlamlı ilişki saptanmamakla birlikte yaş arttıkça başarı şansının düştüğ̈̈ görüldü $(\mathrm{p}=0,316)$ (Tablo 1$)$.

Tablo 1. IUI başarısı ile yaş ve sperm parametreleri ilişkisi

\begin{tabular}{|c|c|c|c|c|}
\hline & \multicolumn{3}{|c|}{ Gebelik durumu (n, \%) } & $\begin{array}{c}P \\
\text { değeri }\end{array}$ \\
\hline Yaş grupları (yıl) & Yok & Var & Total & \\
\hline$<25$ & $26(22,0)$ & $10(35,7)$ & $36(24,7)$ & \\
\hline $26-30$ & $36(30,5)$ & $8(28,6)$ & $44(30,1)$ & \\
\hline $31-35$ & $24(20,3)$ & $7(25,0)$ & $31(21,2)$ & 0,316 \\
\hline $36-40$ & $28(23,7)$ & $3(10,7)$ & $31(21,2)$ & \\
\hline$>41$ & $4(3,4)$ & $0(0)$ & $4(2,7)$ & \\
\hline
\end{tabular}

Yıkama öncesi progresif motil sperm yüzdesi (\%)

$\begin{array}{lcccc}<20 & 4(3,7) & 0(0) & 4(2,9) & \\ 21-35 & 13(11,9) & 1(3,7) & 14(10,3) & 0,128 \\ 36-50 & 45(41,3) & 8(29,6) & 53(39,0) & \\ >51 & 47(43,1) & 18(66,7) & 65(47,8) & \end{array}$

Yıkama sonrası motil sperm yüzdesi (\%)

$\begin{array}{lcccc}<50 & 2(1,8) & 0(0,0) & 2(1,5) & \\ 51-70 & 6(5,5) & 0(0,0) & 6(4,4) & \\ 71-80 & 17(15,6) & 0(0,0) & 17(12,5) & 0,043 \\ 81-90 & 51(37,6) & 9(33,3) & 50(36,8) & \\ >91 & 43(39,4) & 18(66,7) & 61(44,9) & \end{array}$

Yıkama öncesi total sperm sayısı $\left(\times 10^{6}\right)$

\begin{tabular}{lcccc}
$<15$ & $1(0,9)$ & $2(7,4)$ & $3(2,2)$ & \\
$16-50$ & $23(21,1)$ & $4(14,8)$ & $27(19,9)$ & 0,187 \\
$51-100$ & $16(14,7)$ & $3(11,1)$ & $19(14,0)$ & \\
$>101$ & $69(63,3)$ & $18(66,7)$ & $87(64,0)$ & \\
\hline
\end{tabular}

Yıkama öncesi total motil sperm sayısı ( $\left.\times 10^{6}\right)$

$<15 \quad 10(\% 9,1) \quad 4(\% 14,8) \quad 14(\% 10,2)$

16-50 $32(\% 29,3) \quad 10(\% 37,0) \quad 42(\% 30,8)$

51-100 $45(\% 41,2) \quad 13(\% 48,1) \quad 58(\% 42,6)$

$>101 \quad 22(\% 20,1) \quad 0(\% 0) \quad 22(\% 16,1)$

Yıkama sonrası total motil sperm sayısı $\left(\times 10^{6}\right)$

$<5 \quad 6(5,5) \quad 3(11,1) \quad 9(6,6)$

5,01-10 $13(11,9) \quad 0(0,0) \quad 13(9,6)$

10,01-15 $15(13,8) \quad 2(7,4) \quad 17(12,5) \quad 0,143$

$>15 \quad 75(68,8) \quad 22(81,5) \quad 97(71,3)$

Toplam $109(80,1) \quad 27(19,9) \quad 136(100)$ 


\section{TARTIȘMA}

İntrauterin inseminasyon erkek faktörlü subfertilite veya açıklanamayan infertilitesi olan çiftlerde infertilite tedavisi için yardımlı üremede yaygın olarak kullanılan basit ve invaziv olmayan bir tekniktir. Genellikle in vitro fertilizasyon (IVF) ve intrasitoplazmik sperm enjeksiyonu (ICSI) gibi daha invaziv yardımlı üreme tekniklerine geçilmeden önce denenir. ${ }^{[9]}$ Literatürde IUI sonrası gebelik oranları \%10-20 arasında değişmekte olup ${ }^{[5]}$ çalışmamızın oranları $(\% 19,9)$ literatürle uyumludur.

Etkinliğini birçok faktör etkiler ve bu faktörlerin bilinmesi, IUI başarısı için büyük önem taşır. Semen sonuçlarının yorumlanması, toplama tekniği, analiz yöntemi ve normal değerler gibi birçok değişkene bağlıdır. Geleneksel olarak sperm sayısı, hareketliliği ve yüzdesi normal morfolojiye sahip spermler, semen kalitesini değerlendirmek için kullanılan kriterlerdir. Dünya Sağlık Örgütü’nün referans değerleri semen analizi için, sperm kalitesini değerlendirmede yaygın olarak kullanılmaktadır. Başarılı IUI için semen özelliklerine göre tahmini sperm parametreleri ve eşik değerleri hala tartışmalıdır. ${ }^{[6]}$ Birkaç çalışma, katı kriterler kullanan sperm morfolojisinin ve sperm hazırlandiktan sonra dölleyici hareketli sperm sayısının (IMC), semen kalitesinin IUI sonucu üzerindeki gerçek etkisini değerlendirmek için en önemli sperm parametresi olduğunu doğrulamıştır. ${ }^{[17-19]}$ İntrauterin inseminasyon sikluslarında insemine edilen motil sperm sayısının minimum 1 milyon olması gerektiği yönünde yaygın bir inanış olmakla birlikte, ${ }^{[20,21]}$ insemine edilen motilsperm sayıs $<1$ milyon, 1-2 milyon, 2-5 milyon, 5-10 milyon ve $\geq 10$ olarak sınıflandırılan bir çalışmada gebelik oranları sıra ile $\% 3,13, \% 8,67, \% 11,89$, $\% 14,75$, \%13,05 olarak bulunmuştur. ${ }^{\left[{ }^{[9]}\right.}$ Miller ve ark. 10 milyondan az işlenmiş toplam hareketli spermi olan çiftler için önemli ölçüde daha düşük gebelik oranı bildirmiştir. ${ }^{[10]}$ Huang ve ark., son yıkama sonrası toplam hareketli sperm sayısının, gebelik dışı döngülere kıyasla gebelikte önemli ölçüde daha yüksek olduğunu ve bu parametrenin IUI sonrası başarı ile güçlü bir şekilde ilişkili olduğunu ortaya koymuştur. $\mathrm{Bu}$ analizde, yıkama sonrası toplam hareketli sperm sayısı 5 milyonu aştığında gebelik oranlarında istatistiksel olarak önemli gelişmeler görülmüştür. ${ }^{[22]}$ Van Voorhis ve ark. IUI ile optimal doğurganlık oranlarının ortalama TMSC 10 milyon olduğunda elde edildiğini ve bunun IUI veya IVF ile bir çifti tedavi etme kararları için yararlı bir eşik değeri olabileceğini bildirmiştir. ${ }^{[12]}$ Benzer şekilde Kılıçdağ ve ark. da insemine edilen TMSC'nın 10 milyon üzerinde gebelik oranları anlamlı yüksek saptamıştır. ${ }^{[23]}$ Başka bir çalışmada Brasch ve ark., gebe kalma için minimum eşik değer olarak TMSC'yi 3 milyon olarak bildirmiş; bununla birlikte, TMSC 20 milyonu aştı̆̆ında gebelik oranlarında istatistiksel olarak anlamlı iyileşmeler görmüştür. ${ }^{[24]}$ Bizim çalışmamızda da gebelik elde edilen hastaların \%88,1'inde yıkama sonrası TMSC 10 milyonun üzerindeydi. Bununla birlikte, izole erkek faktörü infertilitesi olan çiftleri içeren diğer çalışmalarda, yıkama sonrası TMSC gebelik oluşumu ile ilişkili değildi. ${ }^{[25,26]}$ TMSC ve insemine edilen hareketli sperm sayısının prognostik kullanılabilirliği ve IUI sonucu üzerindeki etkisi ile ilgili tartısmalar halen devam etmektedir. Çalışmamızda, yıkama öncesi TMSC'nin gebelik oluşumu ile anlamlı ilişkisi yok iken yıkama sonrası hareketli sperm yüzdesi gebelik olan grupta olmayan gruba göre istatistiksel olarak anlamlı yüksekti.

Zhao ve ark. ilk örnekteki sperm hareketliliğinin IUI ile ilişkili gebeliği etkileyen bağımsız bir faktör olduğunu bildirdi. ${ }^{[27]}$ Benzer şekilde Hendin ve ark. sperm hareketliliğinin başarılı IUI sonucu ile ilişkili olduğunu bildirdi, ancak bu çalışma ilk semen örneğindeki hareketlilikten ziyade yıkama sonrası hareketliliğe atıfta bulundu. ${ }^{[28]}$ Bizim çalışmamızda ise yıkama öncesi motil sperm yüzdesi gebelik oluşumu ile anlamlı bir ilişkiye sahip değil iken yıkama sonrası motil sperm yüzdesinin artmasının gebelik oluşumu ile istatistiksel olarak anlamlı ilişkisi vardı.

\section{SONUÇ}

Açıklanamayan infertilite olgularında IUI etkili ve güvenli bir tedavi yöntemidir. İnseminasyon öncesi ve yıkama sonrası semen parametreleri ile yıkama yöntemi başarıyı etkileyen faktörlerdir. Bu faktörlerin iyi analizi ile doğru hasta seçiminin yapılması önemlidir.

\section{Etik Kurul Onayı}

Çalışma, Aydın Adnan Menderes Üniversitesi Tıp Fakültesi, Girişimsel Olmayan Klinik Araştırmalar Etik Kurulu tarafından onaylandı. (onay tarihi ve sayısı: 01.10.2020/3).

Hakem Değerlendirmesi

Dış bağımsız.

Çıkar Çatışması

Yazarlar çıkar ilişkisi olmadığını beyan etmişlerdir.

\section{Finansal Destek}

Herhangi bir mali destek alınmamıştır.

\section{Ethics Committee Approval}

The study was approved by Aydın Adnan Menderes University Faculty of Medicine, NonInvasive Clinical Research Ethics Committee. (date and number of approval: 01.10.2020/3)

\section{Peer-review}

Externally peer-reviewed.

Conflict of Interest

No conflict of interest was declared by the authors.

Financial Disclosure

No financial support has been received.

\section{KAYNAKLAR}

1. Moghissi KS, Wallach EE. Unexplained infertility. Fertil Steril 1983;39:5-21. [CrossRef]

2. Guzick DS, Grefenstette I, Baffone K, Berga SL, Krasnow JS, Stovall DW, Naus GJ. Infertility evaluation in fertile women: a model for assessing the efficacy of infertility testing. Hum Reprod 1994;9:2306-10. [CrossRef] 
3. Garceau L, Henderson J, Davis LJ, Petrou S, Henderson LR, McVeigh E, et al. Economic implications of assisted reproductive techniques: a systematic review. Hum Reprod 2002;17:3090-109. [CrossRef]

4. Zegers-Hochschild F, Nygren KG, Adamson GD, de Mouzon J, Lancaster P, Mansour R, Sullivan E. International Committee Monitoring Assisted Reproductive Technologies. The ICMART glossary on ART terminology. Hum Reprod 2006;21:1968-70. [CrossRef]

5. Bai F, Wang DY, Fan YJ, Qiu J, Wang L, Dai Y, Song L. Assisted reproductive technology service availability, efficacy and safety in mainland China:2016. Hum Reprod 2020;35:446-52. [CrossRef]

6. Dickey RP, Pyrzak R, Lu PY, Taylor SN, Rye PH. Comparison of the sperm quality necessary for successful intrauterine insemination with World Health Organization threshold values for normal sperm. Fertil Steril 1999;71:684-9. [CrossRef]

7. Sakhel K, Schwarck S, Ashraf M, Abuzeid M. Semen parameters as determinants of success in 1662 cycles of intrauterine insemination after controlled ovarian hyperstimulation. Fertil Steril 2005;84:248-9. [CrossRef]

8. Karabinus DS, Gelety TJ. The impact of sperm morphology evaluated by strict criteria on intrauterine insemination success. Fertil Steril 1997;67:536-41. [CrossRef]

9. Wainer R, Albert M, Dorion A, Bailly M, Bergère M, Lombroso $\mathrm{R}$, et al. Influence of the number of motile spermatozoa inseminated and of their morphology on the success of intrauterine insemination. Hum Reprod 2004;19:2060-5. [CrossRef]

10. Miller DC, Hollenbeck BK, Smith GD, Randolph JF, Christman GM, Smith YR, et al. Processed total motile sperm count correlates with pregnancy outcome after intrauterine insemination. Urology 2002;60:497-501. [CrossRef]

11. Papillon-Smith J, Baker SE, Agbo C, Dahan MH. Pregnancy rates with intrauterine insemination: comparing 1999 and 2010 World Health Organization semen analysis norms. Reprod Biomed Online 2015;30:392-400. [CrossRef]

12. Van Voorhis BJ, Barnett M, Sparks AE, Syrop CH, Rosenthal G, Dawson J. Effect of the total motile sperm count on the efficacy and cost-effectiveness of intrauterine insemination and in vitro fertilization. Fertil Steril 2001;75:661-8. [CrossRef]

13. Ombelet W, Dhont N, Thijssen A, Bosmans E, Kruger T. Semen quality and prediction of IUI success in male subfertility: a systematic review. ReprodBiomed Online 2014;28:300-9. [CrossRef]

14. Tomlinson MJ, Amissah-Arthur JB, Thompson KA, Kasraie JL, Bentick B. Prognostic indicators for intrauterine insemination (IUI): statistical model for IUI success. Hum Reprod 1996; 11:1892-6. [CrossRef]

15. O'Flaherty C, Lamirande E, Gagnon C. Positive role of reactive oxygen species in mammalian sperm capacitation: triggering and modulation of phosphorylation events. Free Radic Biol Med 2006;41:528-40. [CrossRef]
16. Agarwal A, Saleh RA, Bedaiwy MA. Role of reactive oxygen species in the pathophysiology of human reproduction. Fertil Steril 2003;79:829-43. [CrossRef]

17. Van Waart J, Kruger TF, Lombard CJ, Ombelet W. Predictive value of normal sperm morphology in intrauterine insemination (IUI): a structured literature review. Hum Reprod Update 2001;7:495500. [CrossRef]

18. Hauser R, Yogev L, Botchan A, Lessing JB, Paz G, Yavetz H. Intrauterine insemination in male factor subfertility: significance of sperm motility and morphology assessed by strict criteria. Andrologia 2001;33:13-7. [CrossRef]

19. Van Weert JM, Repping S, Van Voorhis BJ, van der Veen F, Bossuyt PM, Mol BWJ. Performance of the postwash total motile sperm count as a predictor of pregnancy at the time of intrauterine insemination: a meta-analysis. Fertil Steril 2004;82:612-20. [CrossRef]

20. Berg U, Brucker C, Berg FD. Effect of motile sperm count after swim-up on outcome of intrauterine insemination. Fertil Steril 1997;67:747-50. [CrossRef]

21. Wainer R, Merlet F, Bailly M, Lombroso R, Camus E, Bisson JP. Prognosis for intrauterine insemination with partner's sperm according to the characteristics of the spermatozoa. Contracept Fertil Sex 1996;24:897-903.

22. Huang HY, Lee CL, Lai YM, Chang MY, Wang HS, Chang SY, Soong YK. The impact of the total motile sperm count on the success of intrauterine insemination with husband's spermatozoa. J Assist Reprod Genet 1996;13:56-63. [CrossRef]

23. Kılıçdağ EB, Bağış T, Haydardedeoğlu B, Tarım E, Aslan E, Erkanlı $S$, et al. İntrauterin İnseminasyon (Iuı) Sikluslarında Gebelik Sonuçlarını Etkileyebilecek Prognostik Faktörler. Turk J Obstet Gynecol 2005;2:223-8. http://cms.galenos.com.tr/Uploads/ Article_9358/223-228.pdf

24. Brasch JG, Rawlins R, Tarchala S, Radwanska E. The relationship between total motile sperm count and the success of intrauterine insemination. Fertil Steril 1994;62:150-4. [CrossRef]

25. Terada Y, Fukaya T, Haraya H, Yajima A. Sperm motility characteristics and pregnancy outcome of artificial insemination with husband's semen formale infertility. Tohoku J Exp Med 1995;177:337-41. [CrossRef]

26. Milingos S, Comhaire FH, Liapi A, Aravantinos D. The value of semen characteristics and tests of sperm function in selecting couples for intrauterine insemination. Eur J Obstet Gynecol Reprod Biol 1996;64:115-8. [CrossRef]

27. Zhao Y, Vlahos N, Wyncott D, Petrella C, Garcia J, Zacur H, Wallach EE. Impact of semen characteristics on the success of intrauterine insemination. J Assist Reprod Genet 2004;21:143-8. [CrossRef]

28. Hendin BN, Falcone T, Hallak J, Nelson DR, Vemullapalli S, Goldberg J, et al. The effect of patient and semen characteristics on live birth rates following intrauterine insemination: a retrospective study. J Assist Reprod Genet 2000;17:245-52. [CrossRef] 